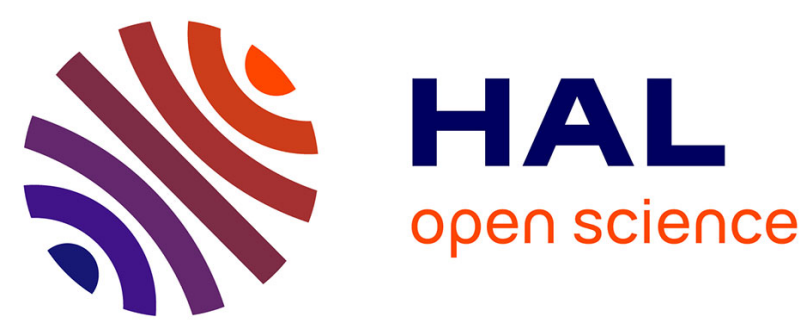

\title{
SIMS DETERMINATION OF THE SURFACE LITHIUM DEPLETION ZONE IN Al-Li ALLOYS BY QUANTITATIVE IMAGE ANALYSIS
}

N. Thorne, A. Dubus, Jérôme Lang, F. Degreve, P. Meyer

\section{- To cite this version:}

N. Thorne, A. Dubus, Jérôme Lang, F. Degreve, P. Meyer. SIMS DETERMINATION OF THE SURFACE LITHIUM DEPLETION ZONE IN Al-Li ALLOYS BY QUANTITATIVE IMAGE ANALYSIS. Journal de Physique Colloques, 1987, 48 (C3), pp.C3-521-C3-526. 10.1051/jphyscol:1987360 . jpa00226591

\section{HAL Id: jpa-00226591 https://hal.science/jpa-00226591}

Submitted on 1 Jan 1987

HAL is a multi-disciplinary open access archive for the deposit and dissemination of scientific research documents, whether they are published or not. The documents may come from teaching and research institutions in France or abroad, or from public or private research centers.
L'archive ouverte pluridisciplinaire HAL, est destinée au dépôt et à la diffusion de documents scientifiques de niveau recherche, publiés ou non, émanant des établissements d'enseignement et de recherche français ou étrangers, des laboratoires publics ou privés. 
SIMS DETERMINATION OF THE SURFACE LITHIUM DEPLETION ZONE IN AI-Li ALLOYS BY QUANTITATIVE IMAGE ANALYSIS

\author{
N. THORNE, A. DUBUS, J.M. LANG, F. DEGREVE and P. MEYER \\ Cégédur-Péchiney, Centre de Recherche et Développement, \\ B.P. 27, F-38340 Voreppe, France
}

\begin{abstract}
The heat treatment of $\mathrm{Al}-\mathrm{Li}$ alloys induces a $\mathrm{Li}$ depletion zone of up to $100 \mu \mathrm{m}$ beneath the metal surface. Characterisation of the Li concentration profile is not possible using conventional Energy Dispersive X-Ray (EDX) based techniques as they are limited to "heavy elements" (At. No $>5$ ). Secondary Ion Mass Spectrometry (SIMS) has no such limit and "long range" quantitative Li depth profiles may be obtained from polished cross-sections. The advent of direct ion imaging allied with quantitative image analysis provides two major improvements over traditional "line-scans": optimised lateral (depth) resolution of $1 \mu \mathrm{m}$ and acquisition times reduced by a factor of about 100 .
\end{abstract}

\title{
1. INTRODUCTION
}

During the heat treatment of $\mathrm{Al}-\mathrm{Li}$ alloys, especially solution heat treatment at temperatures $>500^{\circ} \mathrm{C}$, the strong reactivity of $\mathrm{Li}$ creates a relatively thick surface layer composed primarily of $\mathrm{Li}_{2} \mathrm{CO}_{3}$. This reaction product does not provide a protective barrier film. The bulk of the alloy acts as a Li reservoir for the continuing reaction, resulting in a $\mathrm{Li}$ depletion zone extending up to as much as $100 \mu \mathrm{m}$ beneath the metal surface. Heat treatment parameters (temperature, duration and atmosphere) may be altered so as to control or limit the extent of the depletion zone which may otherwise have consequences on the mechanical properties of thin semi-products $<3 \mathrm{~mm}$ in section.

From the analytical point of view the determination of $\mathrm{Li}$ depth profiles and hence characterisation of the $\mathrm{Li}$ depletion zone presents a problem, as conventional techniques relying on Energy Dispersive X-ray (EDX) analysis cannot detect light elements such as $\mathrm{Li}$ (atomic $\mathrm{N}^{\circ}<5$ ). Indirect methods of measuring the depletion zone have been attempted, and include microhardness profiles and precipitation/etch techniques. Apart from being only indirect, these methods are also rather long, alloy dependent, and difficult to quantify. Secondary Ion Mass Spectrometry (SIMS), increasingly used in material science, is not limited to "heavy" elements and may be used to investigate the entire periodic table $(\mathrm{H} \rightarrow \mathrm{U})$ with excellent sensitivity of $10^{-6}$ to $10^{-9} \mathrm{~g} / \mathrm{g}$ (1)(2). In the following, the methodology used for obtaining quantitative Li depth profiles between the surface and bulk of Al-Li samples is detailed. The use of direct ion microscopy and quantitative image analysis techniques to improve the rapidity and ease of analysis are also described.

\section{EXPERIMENTAL PROCEDURE}

SIMS analysis was performed using a CAMECA IMS $3 \mathrm{f}$ direct imaging ion microscope. The samples were bombarded by a mass filtered primary beam of $\mathrm{Ar}^{+}$ions with an energy of $12.5 \mathrm{keV}$. The sample surface was flooded with oxygen to obtain the maximum sensitivity and stability of the secondary ion signals.

The general method of quantitative SIMS analysis used relies on the fact that the intensity of the secondary ion $\mathrm{X}^{+}$, normalised with respect to the intensity of the matrix ion $\mathrm{M}^{+}$(to eliminate instrument parameters), is proportional to the concentration of element $\mathrm{X}$ in the matrix $\mathrm{M}$. Comparison with carefully prepared standard samples of similar composition therefore allows the quantitation of SIMS results ${ }^{(3)}$. 
Basically, three choices are available for SIMS depth profile analysis: conventional bombardment perpendicular to the sample surface or, using polished cross-sections prepared perpendicular to the sample surface, line-scan analysis or direct ion imaging. These techniques are illustrated in the schematic diagram of Figure 1 and their respective characteristics compared in Table 1.

Conventional SIMS depth profiles are obtained with excellent depth resolution (about $60 \AA$ ) by gradual sputtering (about $1 \AA / s$ ) of the sample perpendicular to the specimen surface. However,

Figure 1: Schematic diagram illustrating the three modes of performing depth profiles: conventional bombardment perpendicular to the surface (limited to the first few microns), a line-scan across a polished cross-section ("long-range") or direct ion imaging combined with quantitative image analysis (profile up to $400 \mu \mathrm{m}$, rapid acquisition).

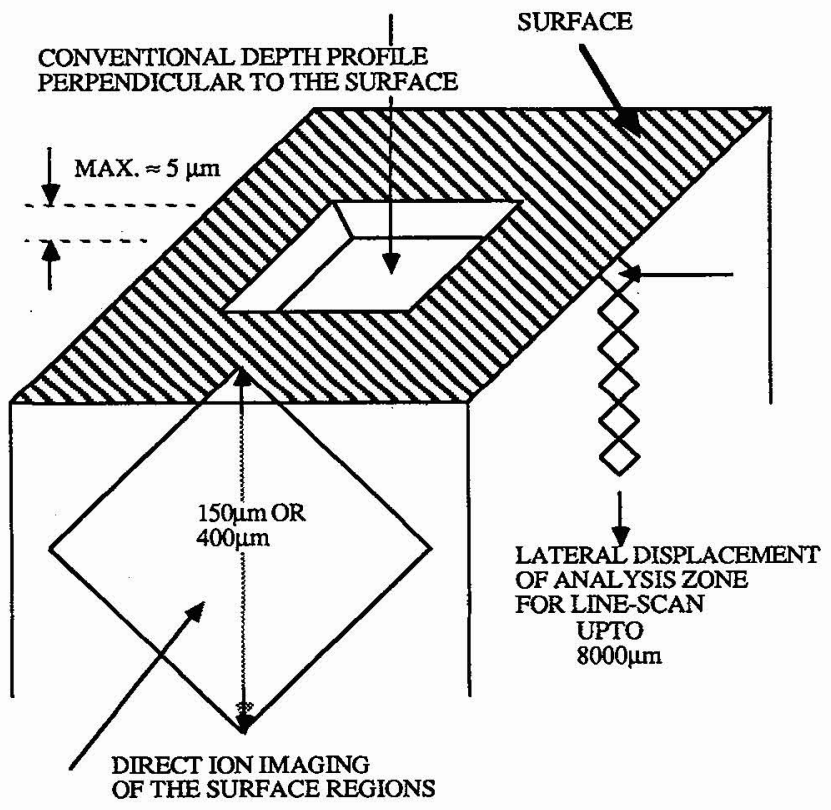

Table 1 : Comparison of the characteristics associated with the three depth profile modes illustrated in Figure 1.

\begin{tabular}{|c|c|c|c|}
\hline operating mode & depth resolution & max. depth & acquisition time \\
\hline $\begin{array}{l}\text { Conventional } \\
\text { bombardement } \\
\text { perpendicular to the } \\
\text { sample surface }\end{array}$ & $50 \AA-100 \AA$ & $\approx 5 \mu \mathrm{m}$ & up to several hours \\
\hline $\begin{array}{l}\text { Line scan on cross- } \\
\text { section perpendicu- } \\
\text { lar to the sample } \\
\text { surface }\end{array}$ & $\begin{array}{l}\text { analysis zone } \\
\text { diameter ( } 1 \text { to } \\
8 \mu \mathrm{m})\end{array}$ & $8000 \mu \mathrm{m}$ & $\begin{array}{l}\approx 1 \text { hour / } 200 \text { data } \\
\text { points }\end{array}$ \\
\hline $\begin{array}{l}\text { direct ion images } \\
\text { of cross-section } \\
\text { perpendicular to } \\
\text { the sample surface }\end{array}$ & $\begin{array}{l}\text { same as lateral } \\
\text { image resolution } \\
\text { (about } 1 \mu \mathrm{m} \text { ) }\end{array}$ & 150 or $400 \mu \mathrm{m}$ & $\begin{array}{l}1 \text { minute / image } \\
+5 \text { minutes image } \\
\text { analysis }\end{array}$ \\
\hline
\end{tabular}


this is only valid for the first few microns of material and cannot be used for "long-range" concentration profiles. This may be overcome by the lateral analysis of polished cross-sections prepared perpendicular to the sample surface. Considerable attention must be paid to the polishing quality at the sample edge (corresponding to the surface) so as to avoid bevelling. A lateral SIMS "line-scan" analysis is performed by displacing a variable analysis zone ( 1 to $8 \mu \mathrm{m}$ diameter) across the section and obtaining the ratio ${ }^{7} \mathrm{Li}^{+} / 27 \mathrm{Al}^{+}$at each point. Considering typical sputter etch rates and the analysis time at each step, each data point corresponds to a sputtered depth of up to $500 \AA$ (a volume corresponding to about $1 \times 10^{-14} \mathrm{~g}$ of aluminium). The "depth" resolution of the resultant profile is directly proportional to the diameter of the chosen analysis zone (ie, 1 to $8 \mu \mathrm{m}$ ).

In the ion microscope, secondary ion images of the sample are produced by stigmatic ion optics and as such the entire image of up to $400 \times 400 \mu \mathrm{m}$ is quasi-instantaneously projected onto a multi-channel plate detector. The image resolution of about $1 \mu \mathrm{m}$ is independent of the primary ion beam diameter. An improved version of the standard image acquisition system has been used, and comprises an ultra-sensitive video camera (individual ion sensitivity) connected to a real-time image processor allowing image averaging/integration routines. The final image is then transferred to a Kontron image analyser for storage in digital form (4).

2D quantitative elemental maps are produced in much the same way as for a line-scan. In a given zone the ${ }^{7} \mathrm{Li}^{+}$and ${ }^{27} \mathrm{Al}^{+}$images are obtained and stored in digital form by the image analyser (up to $500 \AA$ of material is generally required to achieve statistically correct ion images). At each image point (pixel) the ratio ${ }^{7} \mathrm{Li}^{+} / 27 \mathrm{Al}^{+}$is then calculated and compared to a standard for quantification. By retrospective image analysis the $\mathrm{Li}$ concentration at any pixel can be obtained so as to produce, for example, a 1D line profile. Two major advantages are inherent in this procedure: the lateral resolution is optimised (about $1 \mu \mathrm{m}$ ) and each image point or pixel of about $1 \mu \mathrm{m}^{2}$ is simultaneously analysed, resulting in a gain of $>10^{2}$ in acquisition time.

\section{RESULTS AND DISCUSSION}

\subsection{Verification}

The stigmatic ion optics of the ion microscope are susceptible to variation of the field lines extending between the sample surface and the extraction lens. In the case of polished cross-sections where the specimen edge is of importance, edge effects due to sample bevelling may well introduce an experimental error. The validity of the SIMS line scans was therefore verified by making use of a second reference technique, the Nuclear Microprobe (NM), which does not rely on an extraction field. In this technique the $\mathrm{Li}$ concentration was obtained by the nuclear reaction ${ }^{7} \mathrm{Li}(\mathrm{p}, \alpha)^{8} \mathrm{Be}$ induced by bombarding the specimen with a proton beam of $1.2 \mathrm{MeV}$. A lateral line scan was performed by scanning a focused primary beam of $5 \times 5 \mu \mathrm{m}^{2}$ across the cross-section ${ }^{(5)}$. The SIMS and NM results obtained on the same specimen are shown in Figure 2. The two curves are identical within experimental error and confirm the validity of the SIMS approach.

In fact, ion images of the matrix element obtained near the edge of the cross-section show that minor edge effects are present and affect the intensity of secondary ion signals within the first few microns from the surface. However, as the edge effects are the same for each secondary ion, normalisation with the matrix ion allows a satisfactory correction.

\subsection{Li depth profiles as a function of heat treatment conditions}

The above methodology is demonstrated in Figure 3 for the case of an Al-Li alloy ( 8090 $\mathrm{CP} 271$ ) which was chemically milled (reference condition without $\mathrm{Li}$ depletion) and then solution heat-treated under furnace conditions designed to produce controlled samples with a wide range of $\mathrm{Li}$ depletion zones. This enabled the evaluation of both the heat treatment conditions on the extent of $\mathrm{Li}$ depletion, and the resultant changes in the mechanical properties. Results obtained from two of the specimens are presented:

1) specimen heat treated at $535^{\circ} \mathrm{C}$ for 30 minutes in a molten salt bath

2) specimen heat treated at $535^{\circ} \mathrm{C}$ for 60 minutes in an air furnace

Figures 3a,b and 3d,e present the "raw" images of ${ }^{7} \mathrm{Li}^{+}$and ${ }^{27} \mathrm{Al}^{+}$obtained on the specimen treated in the salt bath and air furnace respectively. Before normalisation the ${ }^{7} \mathrm{Li}^{+}$images are difficult 


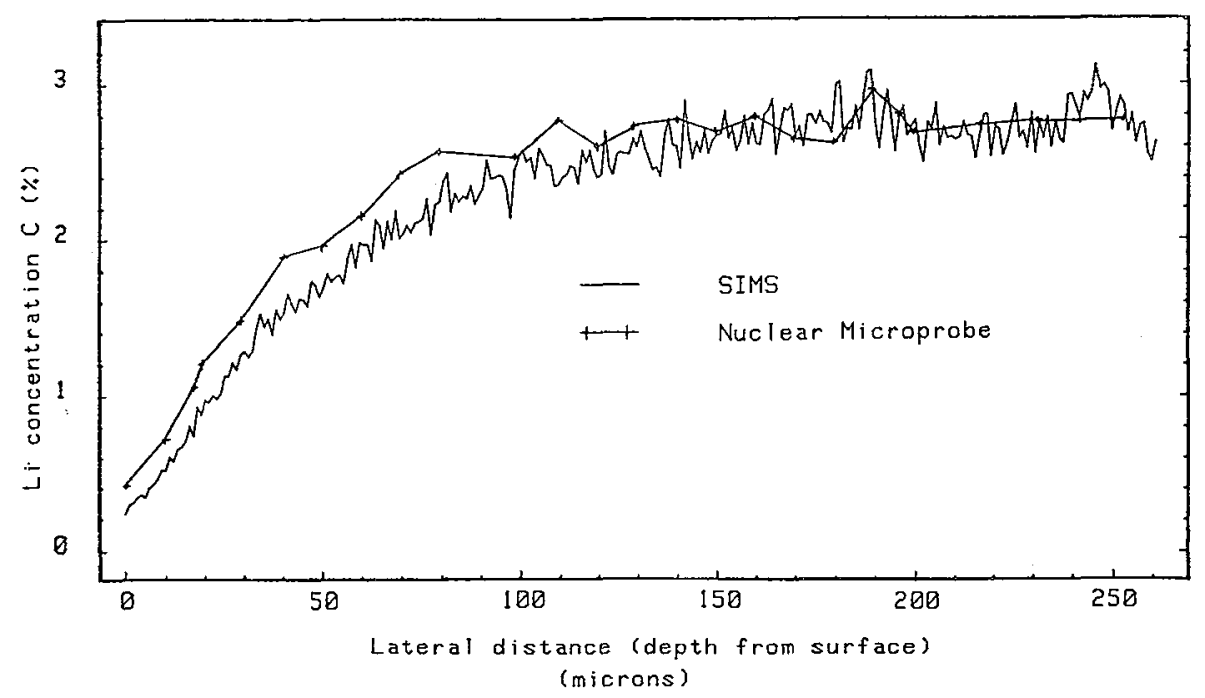

Figure 2: Quantitative Li line-scan depth profiles obtained on the same heat treated Al-Li specimen, using SIMS and the Nuclear Microprobe techniques. The similarity of the two profiles show that edge effects in SIMS do not constitute a source of experimental error, and confirms the use of the NM as a reference technique.

to visually interpret and little difference between the two specimens can be detected. Figures $3 \mathrm{c}$ and $3 \mathrm{f}$ respectively show the resultant quantitative SIMS Li elemental map obtained by pixel normalisation and calibration. The concentration scale has been split into 6 discrete grey levels to aid visual interpretation. It is evident from these quantitative images that the specimen heat treated in an air furnace has undergone significantly greater Li depletion.

The individual pixel intensities (corresponding to about $1 \mu \mathrm{m} \times 1 \mu \mathrm{m}$ of the specimen surface) may by output by the image analyser; a $1 D$ line scan from such an image (in any chosen direction) is therefore a simple matter. Figure 4 presents such profiles obtained for the two specimens from their respective quantitative images along the line $\mathrm{A} \rightarrow \mathrm{B}$. If the $\mathrm{Li}$ depletion zone is defined as the depth below the surface at which the Li concentration is $90 \%$ of the bulk concentration, Figure 4 suggests a depth of approximately $30 \mu \mathrm{m}$ and $60 \mu \mathrm{m}$ respectively for the specimen heat treated in a salt bath and in an air furnace respectively.

\section{CONCLUSION}

The Li depletion zone created beneath the metal surface during the solution heat-treatment of Al-Li alloys may be of considerable importance for the mechanical properties of thin sheet products. Conventional analysis techniques are not capable of detecting light elements and hence qualitative indirect techniques have been tried. SIMS provides an ideal technique allowing the quantitative determination of Li depth profiles. Recent advances in quantitative SIMS ion microscopy and image analysis allow an extremely rapid method of directly observing the extent of $\mathrm{Li}$ depletion, ie. as a function of heat-treatment parameters.

\section{Acknowledgements}

Domeyne.

The authors would like to thank the technical assistance of M. Dussoulliez, D.Terroni and J. 


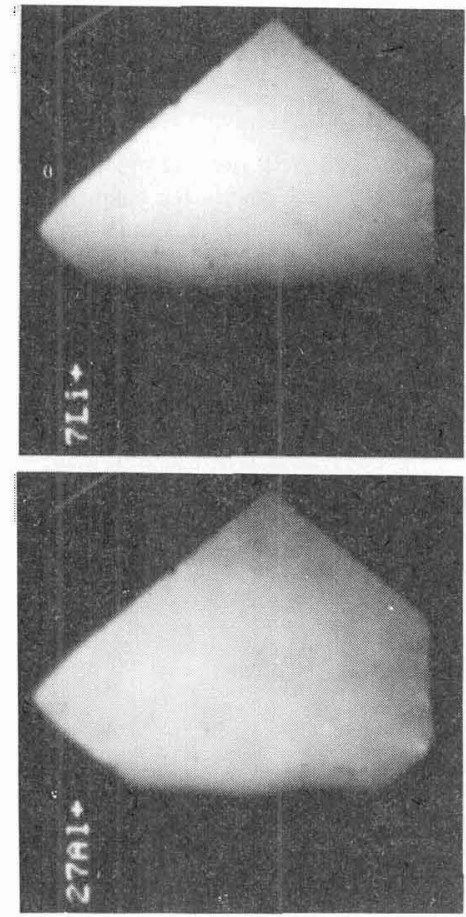

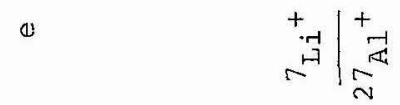
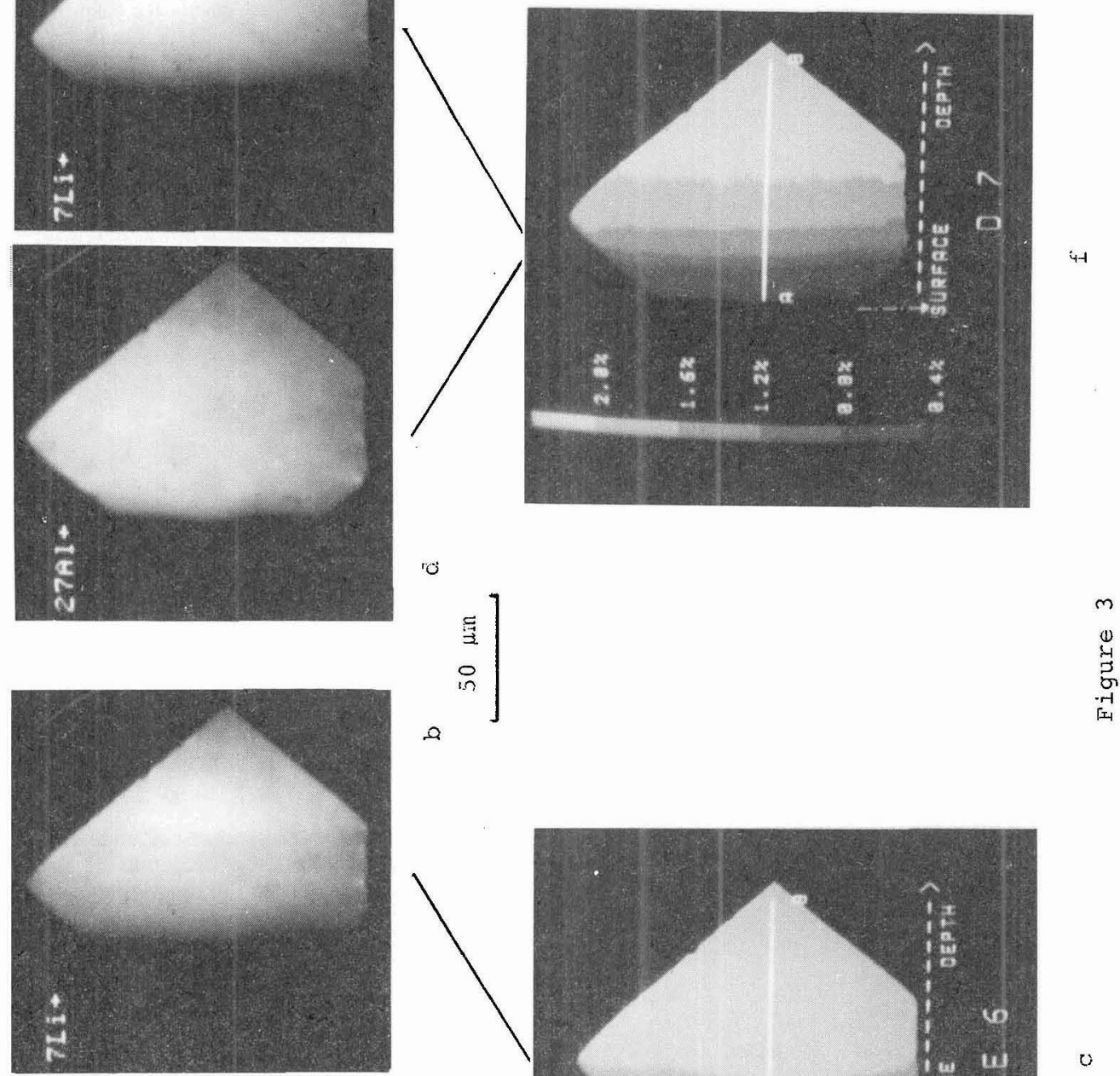

8

है
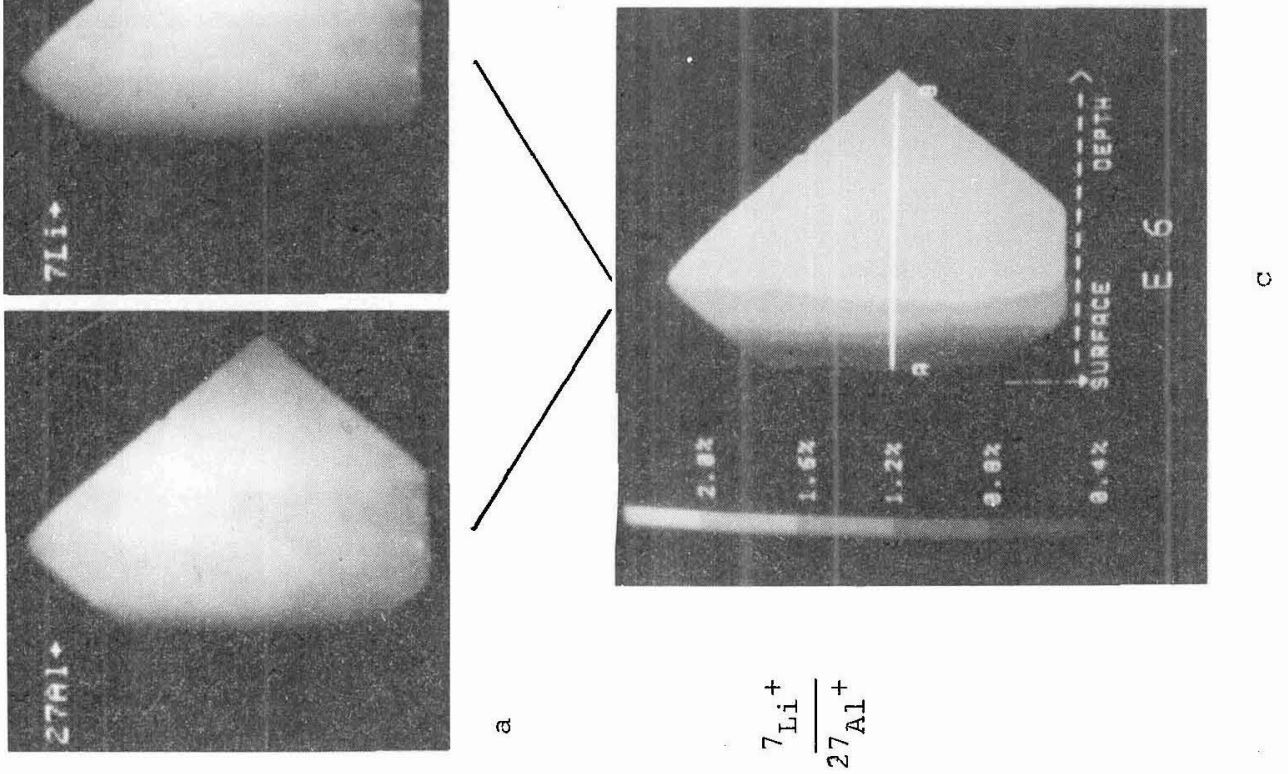
Figure 3: Quantitative ion image analysis demonstrated for the case of two Al-Li alloys, one heat treated in a molten salt bath at $535^{\circ} \mathrm{C}$ for $30^{\prime}\left(3 \mathrm{a}, \mathrm{b}\right.$ and c), the other in an air furnace at $535^{\circ} \mathrm{C}$ for $60^{\prime}$ ( $(\mathrm{d}, \mathrm{e}$ and $\mathrm{f}$ :

- a,b,d and e) "raw" ion images of ${ }^{7} \mathrm{Li}^{+}$and ${ }^{27} \mathrm{Al}^{+}$

- $c$ and $\mathrm{f}$ ) guantitative $\mathrm{Li}$ maps produced by normalising the ${ }^{7} \mathrm{Li}^{+}$images with their respective matrix ${ }^{27} \mathrm{Al}^{+}$image. The Li concentration scale, split into 6 discrete grey levels for ease of visual interpretation, was produced by calibration with respect to the known bulk $\mathrm{Li}$ concentration.The lines $\mathrm{A}->\mathrm{B}$ correspond to the 1D line profiles of Figure 4

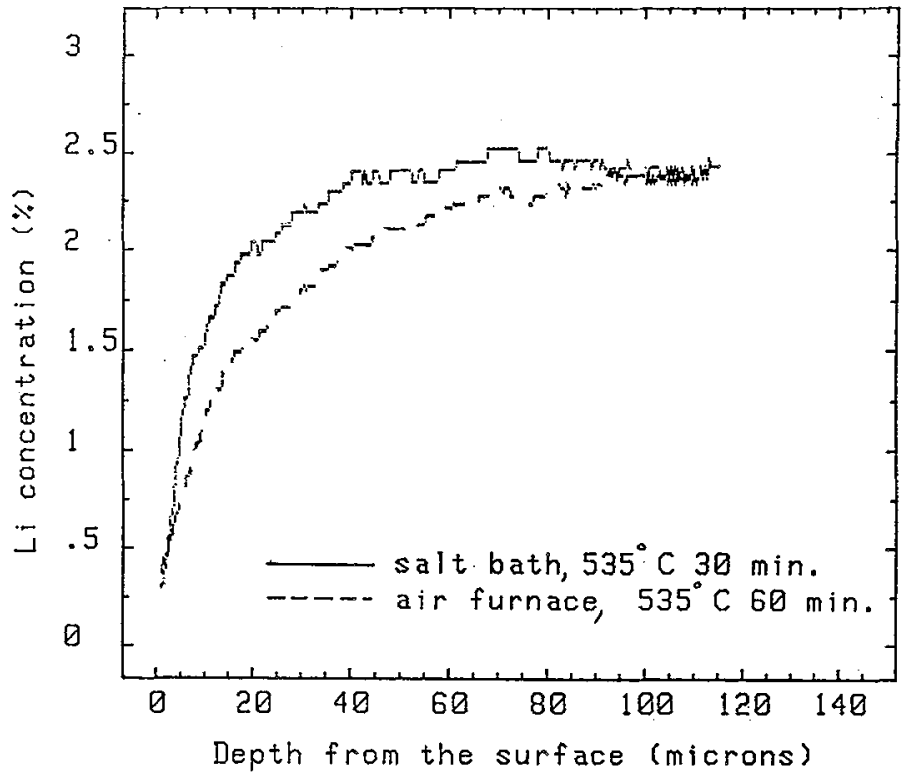

Figure 4: The pixel intensities along the lines A->B of Figures $3 \mathrm{c}$ and $\mathrm{f}$ were used to calculate 1D quantitative Li depth profiles for each specimen. It is evident that the specimen heat treated in the air furnace has suffered significantly more Li depletion than the specimen heat treated in the molten salt bath.

\section{References}

1) G.A. Morrison and G. Slodzian, Anal. Chem., 47, 1975, 942A

2) F. Degrève and J.M. Lang, in Secondary Ion Mas Spectrometry SIMS V, Springer Verlag, Berlin, 1986, 388-393

3) H.W. Werner, Surface and Interface Analysis, 2, $\mathrm{N}^{\circ} 2,1980,56$ - 73.

4) N.A. Thorne, F. Degrève, Scanning Electron Microscopy, IV , 1986, 1255 - 1265.

5) F. Degrève, J.M. Lang, F. Bodart and G. Demortier, Proc. Sème Cong. Soc, Franc. Spectom. Masse, Grenoble, 1986, p87 